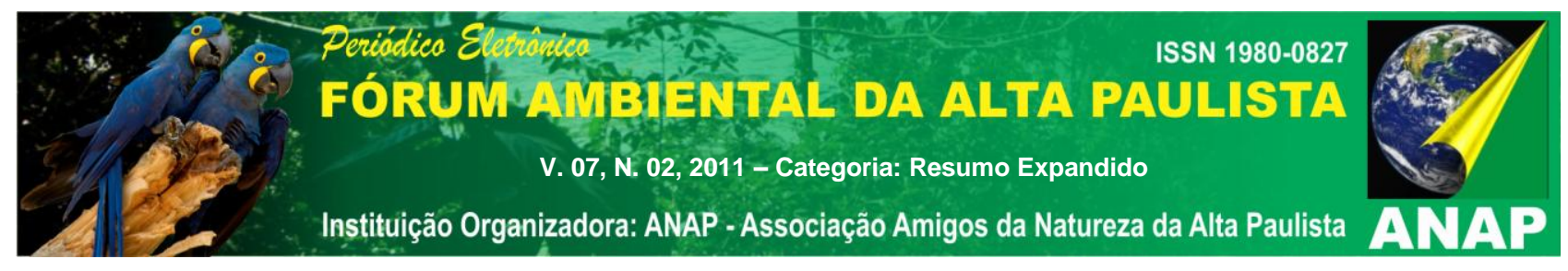

\title{
MONITORAMENTO DA QUALIDADE DA ÁGUA DA MICROBACIA DO CÓRREGO DA OLARIA
}

Nome do Autor Principal:

Maria Conceição Lopes ${ }^{2}$

Nomes dos Co-autores:

Antonio Lucio Mello Martins ${ }^{2}$, Michele Claudia da Silva. ${ }^{1}$ Romulo Sensuline Valaretto 2

Nome do Orientador:

Teresa Cristina Tarlé Pissarra ${ }^{1}$

\section{Instituição ou Empresa}

1)UNESP -Campus de Jaboticabal-SP, Depto de Eng. Rural.

2) APTA - Pólo Regional Centro Norte - Pindorama - SP

\section{Instituição de Fomento}

FEHIDRO,Fundo Estadual de Recursos Hídricos ( FEHIDRO TG 350/2009).

E-mail de contato

, conceicao@apta.sp.gov.br, teresap@fcav.unesp.br

Palavras-chave Recurso Hídrico, Características Geomoforlógicas, Uso do Solo. 


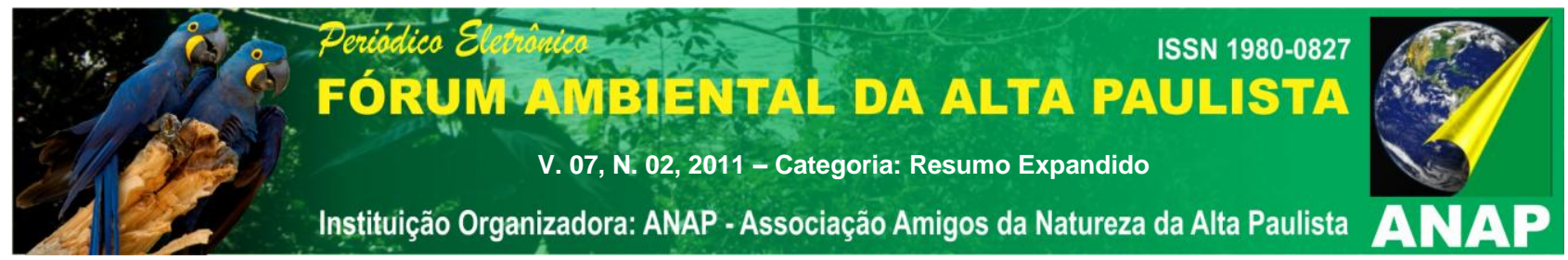

\section{INTRODUÇÃO}

A bacia hidrográfica é uma área de captação natural da água de precipitação que faz convergir o escoamento para um único ponto de saída. Esta área compõe-se de um conjunto de superfícies vertentes e de uma rede de drenagem formada por cursos de água que confluem até resultar em um leito único no seu exutório (Bucci, 1997). A qualidade da água de uma bacia é influenciada por diversos fatores, dentre eles o clima, a cobertura vegetal, a topografia, a geologia, bem como o tipo, o uso e o manejo do solo (Pereira, 1997). Muito mais importante, todavia, são as evidências demonstradas em vários trabalhos experimentais de que é perfeitamente possível, com base no conhecimento do funcionamento da microbacia, realizar operações necessárias à produção florestal com um mínimo de impacto à qualidade da água (Aubertin \& Patric, 1974).

É neste aspecto que reside o fundamento da proposta de se estabelecer um programa permanente de monitoramento da qualidade da água e do uso e ocupação do solo na unidade territorial de microbacias. Primeiro, porque se trata de um método já demonstrado em inúmeras situações e condições, de se poder realmente atribuir o efeito à causa (relação entre o uso florestal e a qualidade da água). Segundo, porque a microbacia pode servir como laboratório natural para estudos de médio e longo prazo, visando à comparação de diferentes práticas de manejo, na busca de critérios de manejo florestal que sejam compatíveis com a minimização de impactos ambientais visando a sustentabilidade.

O uso de microbacias hidrográficas como unidades experimentais teve início por volta do começo deste século em vários países e os inúmeros resultados já obtidos mostram que o uso da terra, as atividades agrícolas e florestais podem afetar não apenas a quantidade e o regime da vazão, a qualidade da água, como também o uso e manejo do solo.

As características físicas de uma bacia constituem elementos de grande importância para avaliação do seu comportamento hidrológico, pois, ao se estabelecerem relações e comparações entre tais características e os dados hidrológicos conhecidos, podem-se determinar indiretamente os valores hidrológicos em locais nos quais faltem dados (VILLELA \& MATTOS, 1975). Segundo, Christofoletti (1970), a análise de aspectos 


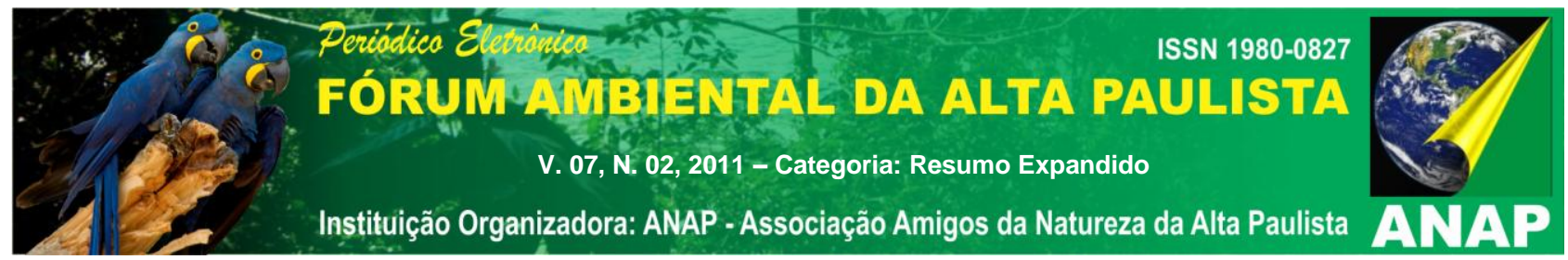

relacionados a drenagem, relevo e geologia pode levar à elucidação e compreensão de diversas questões associadas à dinâmica ambiental local.

Diversos fatores podem alterar a qualidade de água de uma bacia hidrográfica como: declividade, tipo de solo, uso da terra, principalmente nas áreas de recarga que influenciam no armazenamento de água subterrânea e no regime das nascentes e dos cursos d'água. Portanto a conservação desses recursos deve ser pautada nos estudos das interações dessas áreas e das ações antrópicas que nelas ocorrem, pois a conservação da água depende da conservação de outros recursos naturais (PINTO et al 2005 e TUCCI, 2000).

A caracterização da qualidade da água é um elemento essencial para a gestão dos recursos hídricos (ANA, 2005). Há duas formas de caracterizar os recursos hídricos: com relação à sua quantidade e com relação à sua qualidade, estando essas características intimamente relacionadas. A qualidade da água depende diretamente da quantidade de água existente para dissolver, diluir e transportar as substâncias benéficas e maléficas para os seres que compõem as cadeias alimentares.

Segundo Carvalho et al. (2000) existem relações positivas e negativas que podem influenciar os parâmetros físico-químicos em épocas de maior precipitação (verão). Dos parâmetros utilizados a temperatura da água, a turbidez, o pH e a concentração de oxigênio dissolvido foram os mais influenciados pelas estações e também os que melhor discriminaram o local de estudo.

A definição do enquadramento de um determinado corpo hídrico resulta da decisão sobre usos da água e gestão da bacia respectiva e condiciona decisões, tais como as concessões de outorga de direito do uso dos recursos hídricos e o licenciamento ambiental de empreendimentos que ali se instalem. Determina também as necessidades de investimento a serem feitas na bacia com vistas à sustentabilidade do uso da água. É, portanto, informação essencial para a gestão (ANA, 2005).

O presente trabalho tem objetivo de monitorar a qualidade da água, e analisar o uso e ocupação do solo da microbacia "Córrego da Olaria" . Essa microbacia está situada na Unidade Sede da Apta - Pólo Regional Centro Norte, em Pindorama - SP, a qual possui uma área de $11 \mathrm{~km} 2$ e contribui para o Ribeirão São Domingos, pertencente a bacia hidrográfica dos rios Turvo e Grande, e percorre o trecho de $2 \mathrm{~km}$ nos limites da Unidade 


\section{OBJETIVO GERAL}

O presente trabalho teve como objetivo avaliar os aspectos qualitativos dos corpos hídricos relacionando-os com o uso e ocupação do solo na Microbacia Hidrográfica do Córrego da Olaria, situada no Pólo Regional Centro Norte, no Município de PindoramaSP.

\section{OBJETIVO ESPECIFICO}

Realizar o monitoramento da qualidade da água em 8 (oito) pontos de coleta nas nascentes das microbacias de 1.a ordem de magnitude.

\section{METODOLOGIA}

A qualidade da água foi monitorada em 8 (oito) pontos de coleta nas nascentes das microbacias de 1. a ordem de magnitude no período de hum ano de julho de 2010 a junho de 2011. A determinação da temperatura, oxigênio dissolvido, $\mathrm{pH}$, e condutividade elétrica da água foi feita no próprio local da coleta através da leitura direta em aparelhos específicos para leitura da qualidade da água em campo. $\mathrm{O}$ odor foi analisado por percepção humana. A cor aparente foi feita pela comparação com soluções conhecidas de platina-cobalto. A cor verdadeira é medida em unidades de cor dadas pela escala de platina-cobalto, ou escala de Hazen. A escala de cores varia desde um amarelo pálido até o marrom escuro, e foi feita a comparação visual da amostra com uma solução de cloreto de cobalto e cloroplatinato de potássio.

As coletas de amostras da água foram realizadas mensalmente para análise dos parâmetros químicos: $\mathrm{pH}$, oxigênio dissolvido; e físicos: condutividade elétrica com cinco repetições. Foi utilizado o equipamento mod. TEC-RL060P para a coleta dos dados de $\mathrm{pH}$, oxigênio e temperatura; e o condutivímetro Portátil Modelo HI 9835, para a coleta da condutividade. 


\section{RESULTADOS}

Os parâmetros utilizados no monitoramento, demonstrados nos gráficos abaixo, indicaram que mesmo a microbacia estando situada numa região essencialmente agrícola, a qualidade da água apresenta-se adequada para uso tanto uso agrícola quanto para a biota aquática.

A condutividade é a expressão numérica da capacidade de uma água conduzir a corrente elétrica. Depende das concentrações iônicas e da temperatura e indica a quantidade de sais existentes na coluna d'água e, portanto, representa uma medida indireta da concentração de poluentes. Em geral, níveis superiores a $100 \mu \mathrm{S} / \mathrm{cm}$ indicam ambientes impactados. A condutividade também fornece uma boa indicação das modificações na composição de uma água, especialmente na sua concentração mineral, mas não fornece nenhuma indicação das quantidades relativas dos vários componentes. A condutividade da água aumenta à medida que mais sólidos dissolvidos são adicionados. Altos valores podem indicar características corrosivas da água (CETESB, 2009).

Na Figura 3, encontra-se a variação temporal da condutividade elétrica no Córrego da Olaria, onde é possível observar que nos meses de setembro, outubro e fevereiro a condutividade ultrapassou o valor máximo permitido (VMP) estabelecido pela legislação vigente, estes valores coincidiram com as menores precipitações registradas, comprovando que há aumento de concentrações de sais na água em períodos de estiagem. 

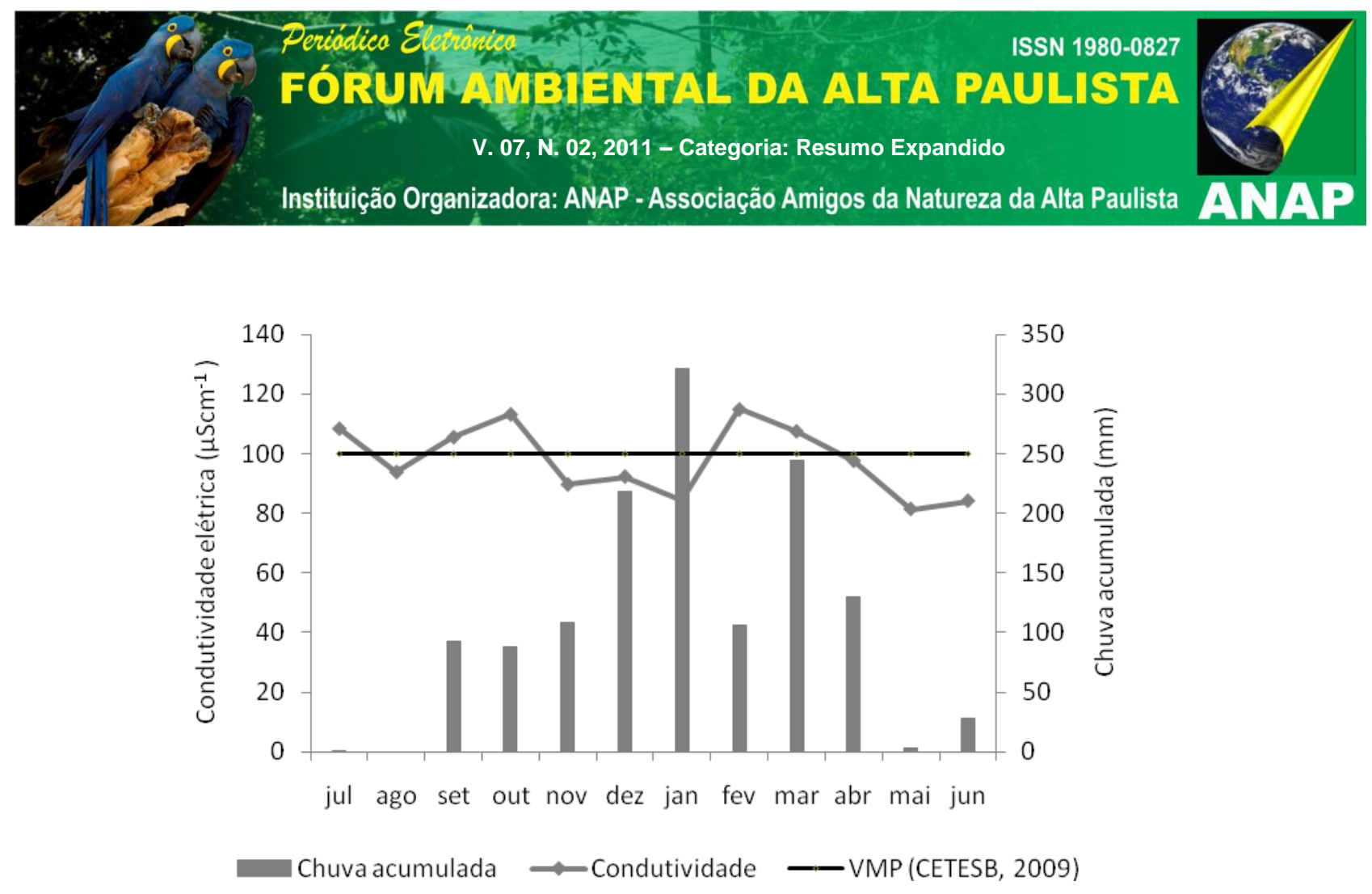

Figura 3. Variação temporal da condutividade elétrica da água a 25ㄷ․

A variação temporal da condutividade elétrica mostrou-se, inversamente proporcional a quantidade de chuva acumulada entre os intervalos de avaliação. Isto ocorre porque, durante o período seco, com a redução do volume de água do córrego, a concentração de sais dissolvidos torna-se maior, ocasionando um aumento na condutividade elétrica.

Por influir em diversos equilíbrios químicos que ocorrem naturalmente ou em processos unitários de tratamento de águas, o pH é um parâmetro importante em muitos estudos no campo do saneamento ambiental.

As faixas de $\mathrm{pH}$ estabelecidas para as diversas classes de águas naturais, tanto de acordo com a legislação federal, quanto pela legislação do Estado de São Paulo são entre 6 e 9. Na Figura 4 observa-se que em todo o período avaliado o $\mathrm{pH}$ do Córrego da Olaria fixou-se dentro dos limites permitidos, indicando uma condição adequada para 0 ecossistema aquático. 

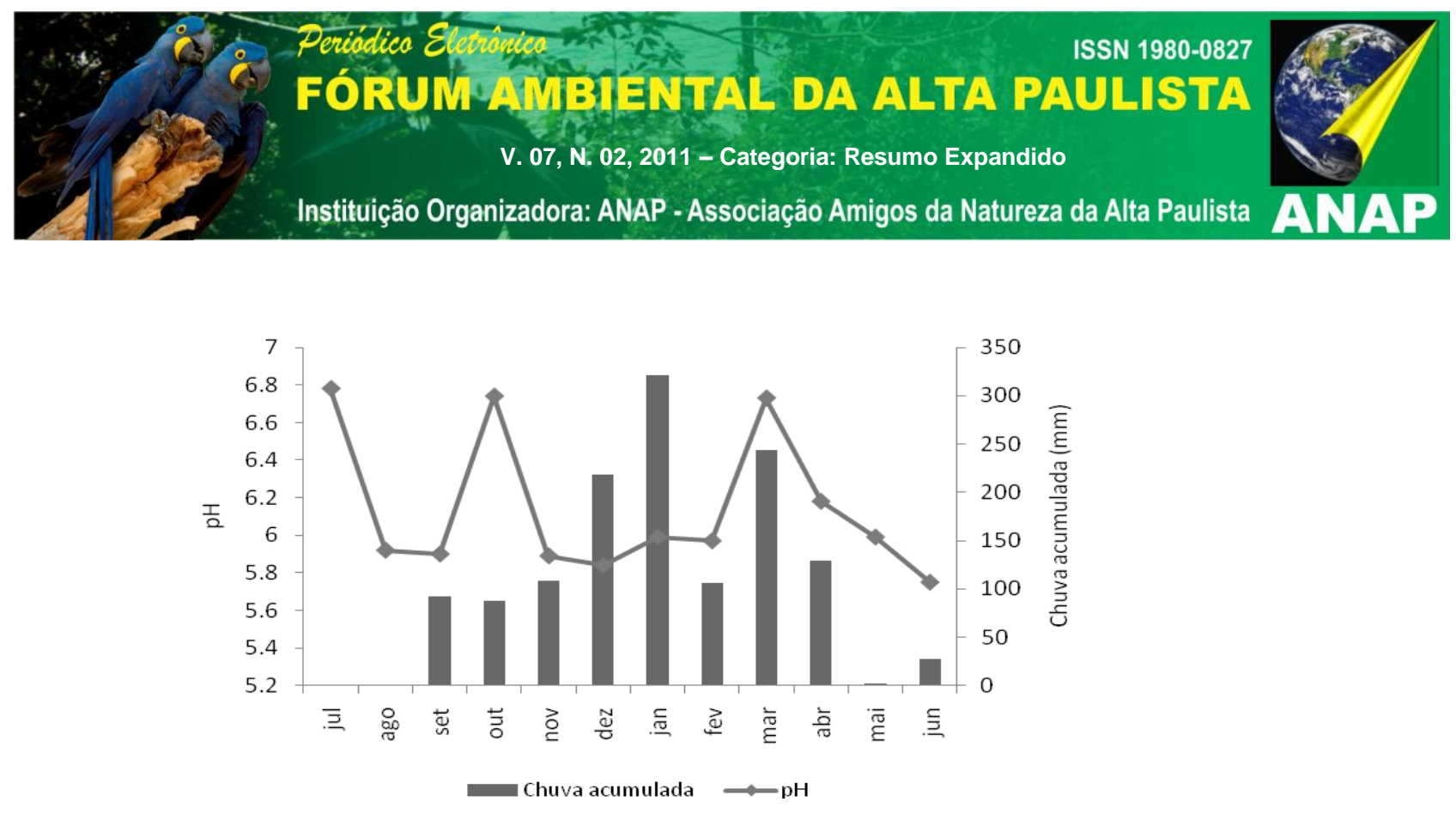

Figura 4. Variação temporal do pH e chuva acumulada no Córrego da Olaria, Pindorama - SP.

No período seco, um fator que pode ter contribuído para o aumento do $\mathrm{pH}$, é a redução da turbidez da água, que ao favorecer a proliferação de algas, promove a assimilação de gás carbônico do meio pelo processo fotossintético, reduzindo assim, a concentração de ácido carbônico na água (MORAES, 2001). Já no período chuvoso, além da água da chuva apresentar naturalmente um pH em torno de 5,0 (TOMAZ, 2003), com o escoamento superficial, quanto maior a área drenada por cada ponto, maior é a quantidade potencial de matéria orgânica transportada para o leito do córrego, resultando em redução nos valores de $\mathrm{pH}$ da água, fato este que, provavelmente, poderia explicar este comportamento nos meses de novembro a fevereiro.

$\mathrm{Na}$ Figura 5 observa-se que nos meses de agosto e setembro os valores de oxigênio dissolvido encontraram-se abaixo do valor mínimo estabelecido pelo CONAMA ( $\left.n^{\circ} 357 / 05\right)$, esses valores coincidiram com um período de baixa precipitação e com a época de manejo do solo no entorno da microbacia, acarretando em arraste de partículas para o leito do córrego. Esse arraste de partículas provoca uma diminuição na concentração de oxigênio da água, pois os microorganismos ao decomporem a matéria 


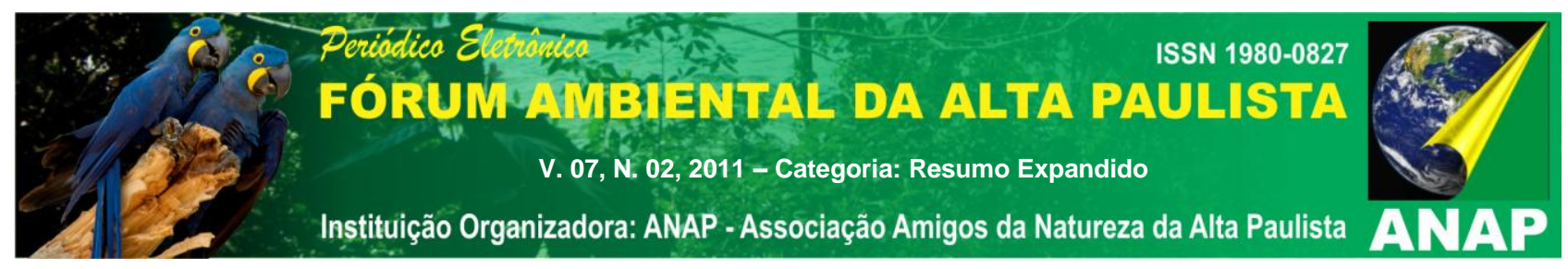

orgânica consomem grande parte do oxigênio disponível na

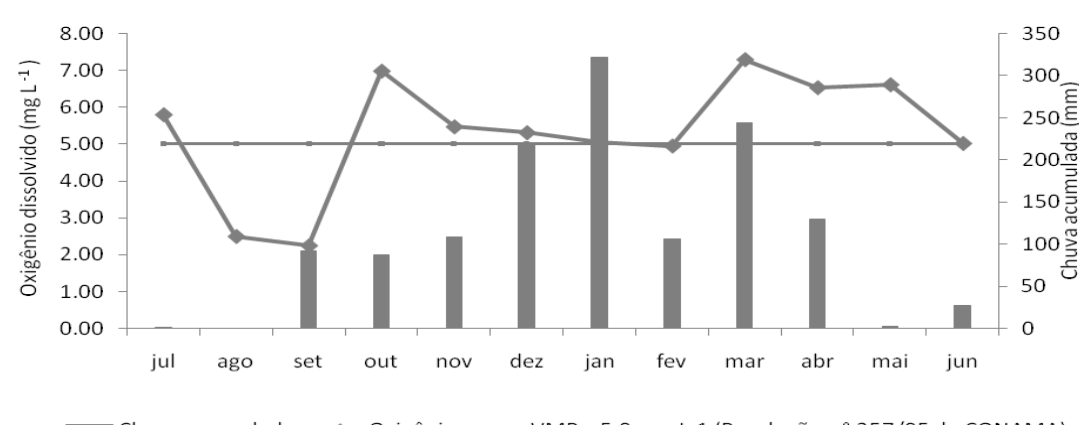

água.

Figura 5. Variação temporal do oxigênio dissolvido e da chuva acumulada no Córrego da Olaria, Pindorama - SP.

Neste trabalho verificou-se também, que a temperatura é o parâmetro mais influenciado pela sazonalidade (Figura 6), devido à localização em latitude de estações do ano razoavelmente definidas, e é provável ainda que, a água na porção final do ribeirão estudado não seja um somatório de características e alterações ao longo do canal, e sim uma água de qualidade final tamponada por regiões de mata ciliar ou diluída pelo volume de água e pela distância percorrida.

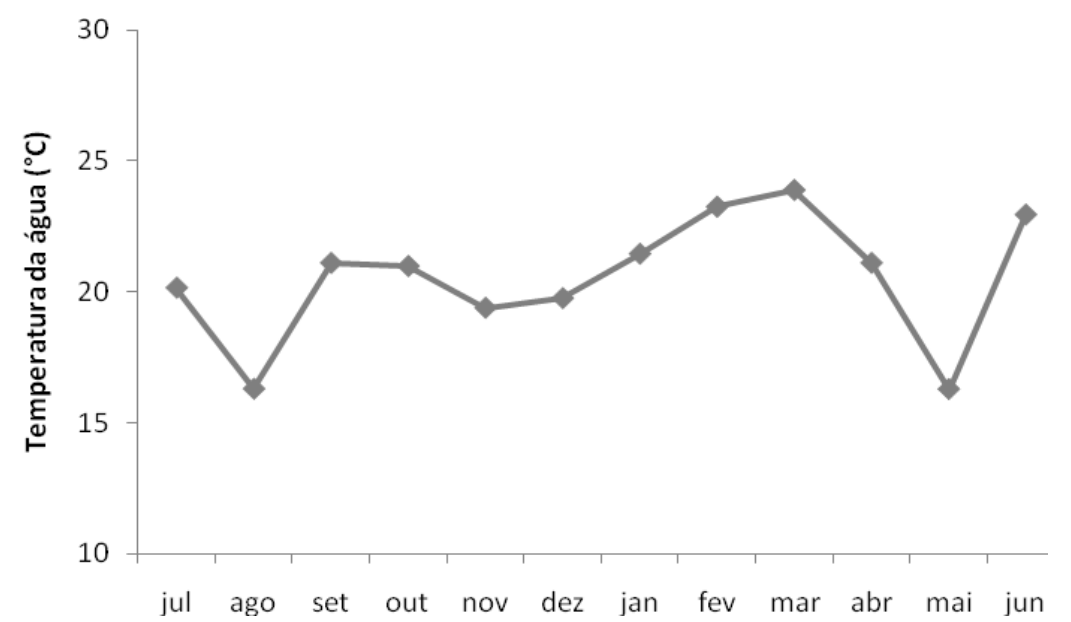

Figura 6. Variação temporal da temperatura no Córrego da Olaria, Pindorama - SP.

A temperatura também influencia a condutividade elétrica, $\mathrm{pH}$, viscosidade da água e solubilização de gases como gás carbônico e oxigênio, sendo um parâmetro importante para o monitoramento e gestão dos recursos hídricos. 


\section{CONSIDERAÇÕES FINAIS}

O estudo consistiu na avaliação dos fatores que influenciam a qualidade da água na Microbacia "Córrego da Olaria". A condutividade elétrica mesmo apresentando valores acima do permitido, não aponta sinais de poluição na microbacia, pois esses aumentos são oriundos da concentração de sais na água no período de estiagem. $\mathrm{O}$ pH apresentou valores adequados em todo o período avaliado, corroborando com a legislação vigente.

O oxigênio dissolvido apresentou em dois meses de avaliação valores abaixo do permitido, porém isso não indica que a microbacia esteja em processo de degradação, apenas que a baixa vazão e o aumento de sólidos nesse período ocasionaram um consumo maior de oxigênio, tornando-se então um fato isolado. A temperatura da água foi o parâmetro mais suscetível a alteração, sendo influenciada pelas modificações do ambiente.

Essa microbacia é importante tendo em vista sua contribuição ao Rio São Domingos que abastece sete municípios do Estado de São Paulo. O Rio segue sempre em direção noroeste e passa pelo município de Pindorama, onde recebe varios afluentes, em seguida passando para o município de Catanduva, onde recebe as águas de varios córregos e sai com o tamanho de um ribeirão. O próximo destino é Catiguá onde recebe varios afluentes e seu primeiro grande afluente (um pequeno ribeirão). De lá segue para Tabapuã e nesta cidade vira seu curso para o norte, e recebendo mais grandes afluentes e outro ribeirão. Em seguida chega ao seu destino final, Uchoa, onde desagua no rio Turvo, já com $160 \mathrm{~km}$

\section{REFERENCIAS}

ALBERTIN, G M;PATRIC JH Water Qualiaty after clear cuting a Small Watershad in West Virginia Journal of Environmental Quality p 243-249, 1974.

ANA - Agência Nacional das Águas. Estudo de Consolidação dos Procedimentos Metodológicos na Elaboração do Relatório de Conjuntura de Recursos Hidricos / Relatório final - RF / Estruturação da Base de Dados. Estudos realizados pela empresa TC/BR Tecnologia e Consultoria Brasileira S/A - Brasília, ANA, SPR, 2005. 118p.

BUCCI, E. F. B. Método de avaliação em bacia hidrografica para análise de classes de uso da terra. S. J. dos Campos: INPE, 1997. 


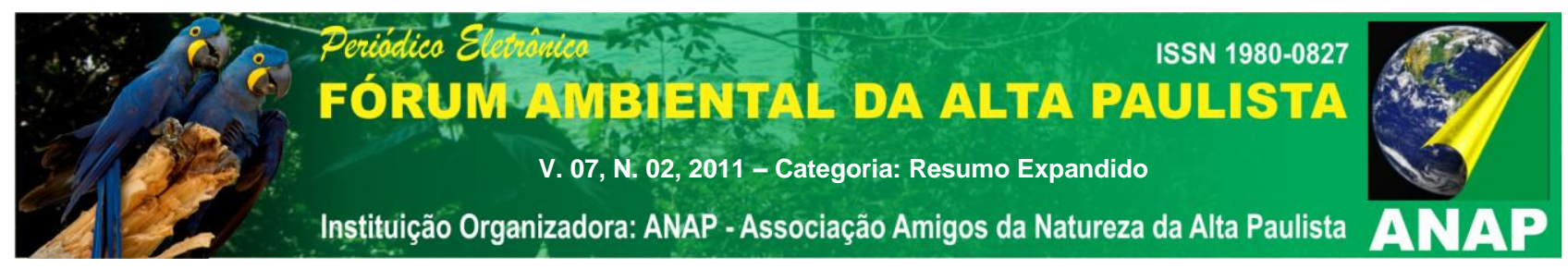

CARVALHO, N. de O.; FILIZOLA JUNIOR, N.P.; SANTOS, P.M.C. dos; LIMA, J.E.F.W. Guia de avaliação de assoreamento de reservatórios. Brasília: ANEEL / Superintendência de Estudos e Informações Hidrológicas, 2000. 132p.

CHRISTOFOLETTI, A. Análise morfométrica de bacias hidrográficas no Planalto de Poços de Caldas. 1970. 375 f. Tese (Livre Docência) - Universidade Estadual Paulista, Rio Claro, 1970.

PEREIRA V.P, Solo: Manejo e controle da erosão hídrica. Jaboticabal, FCAV, 1997 56p.

PINTO, L.V.A.; BOTELHO, S.A.; OLIVEIRA-FILHO, A.T.; DAVIDE, A.C. Estudo da vegetação como subsídios para propostas de recuperação das nascentes da bacia hidrográfica do ribeirão Santa Cruz, Lavras, MG. Revista Árvore [online]. vol.29, n.5, pp. 775-793. ISSN 0100-6762. 2005.

TUCCI, C.E.M. Regionalização de Vazões. ANEEL/ IPH/ UFRGS, Brasil, 167p. 2000.

VILLELA, S.M.; MATTOS, A. Hidrologia Aplicada. São Paulo: McGraw-Hill do Brasil, 1975. 245p. 